\title{
BMJ Open Prevalence, awareness, treatment and control of hypertension among Ngawa Tibetans in China: a cross- sectional study
}

\author{
Tingxin Li, ${ }^{1}$ Ping Shuai, ${ }^{1}$ Jinghong Wang, ${ }^{2}$ Lin Wang (D) ${ }^{1}$
}

To cite: Li T, Shuai P, Wang J, et al. Prevalence, awareness, treatment and control of hypertension among Ngawa Tibetans in China: a crosssectional study. BMJ Open 2021;11:e052207. doi:10.1136/ bmjopen-2021-052207

- Prepublication history and additional supplemental material for this paper are available online. To view these files, please visit the journal online (http://dx.doi.org/10.1136/ bmjopen-2021-052207)

Received 10 April 2021 Accepted 19 August 2021

\section{Check for updates}

(c) Author(s) (or their employer(s)) 2021. Re-use permitted under CC BY-NC. No commercial re-use. See rights and permissions. Published by BMJ.

${ }^{1}$ Health Management Center Sichuan Provincial People's Hospital, University of Electronic Science and Technology of China, Chengdu, Sichuan, China ${ }^{2}$ College of Life Sciences, Shaanxi Normal University, Xi'an, Shaanxi, China

Correspondence to Dr Lin Wang; midaizi1979@163.com and Jinghong Wang; jinhong@snnu.edu.cn

\section{ABSTRACT}

Objectives To explore the prevalence, awareness, treatment and control rate of hypertension and analyse the potential social environment factors among Ngawa Tibetans in China.

Design This was a cross-sectional observational study. Setting The investigation based on a multistage stratified cluster sampling was conducted in the Ngawa area, Sichuan Province, Southwest China. Tibetan residents were selected by random sampling method from one city and six counties in Ngawa.

Methods Basic demographical information, physical activity and blood pressure were collected. In addition, the participants completed the questionnaire. A multivariate logistic regression analysis was used to examine the association between the prevalence, awareness, treatment and control rate of hypertension and the potential risk factors.

Participants The sample comprised 2228 Ngawa Tibetan residents (age 18-80 years) from September 2018 to June 2019.

Results The prevalence rate of hypertension was $24.6 \%$. The control rate was $6.2 \%$, while the awareness rate $(32.3 \%)$ and treatment rate $(21.7 \%)$ of hypertension had been significantly improved.

Conclusion The prevalence of hypertension among Ngawa Tibetans was high. The awareness and treatment were improved in recent years. But the control rate was low. The government needs to strengthen the basic medical care and health education for Ngawa Tibetans.

\section{INTRODUCTION}

High morbidity and mortality of cardiovascular disease are rapidly becoming the leading causes of death worldwide. ${ }^{12}$ Hypertension is a major risk factor for cardiovascular disease, affecting $26.4 \%$ of the world's adult population (972 million), and is expected to increase to $29.2 \%$ (1.56 billion) by $2025 .^{3-5}$ In China, the number of premature deaths caused by hypertension is $\geq 200$ million, and the direct medical costs each year are at least $¥ 36.6$ billion. ${ }^{67}$ As a result, poverty or return to poverty due to illness exists in economically underdeveloped areas. ${ }^{8}$

\section{STRENGTHS AND LIMITATIONS OF THIS STUDY}

$\Rightarrow$ To the best of our knowledge, this is one of the first investigations of hypertension among Ngawa Tibetans after the government's poverty alleviation.

$\Rightarrow$ This study, for the first time, reported the change in awareness, treatment and control rate of hypertension among Ngawa Tibetans.

$\Rightarrow$ The multistage stratified cluster sampling was carried out in Ngawa Tibetan.

$\Rightarrow$ This cross-sectional study was limited in determining the direction of the association.

$\Rightarrow$ Self-filling the questionnaire might cause bias.

The existing data showed that the prevalence of hypertension varies considerably from one region to another and between rural and urban Tibetan populations (from $23.4 \%$ to $51.2 \%) \cdot{ }^{9-13}$ This phenomenon could be attributed to the various branches of the Tibetan population, as well as the differences in living areas, altitudes, lifestyles, economic levels and genetic characteristics. ${ }^{8}{ }^{9}$ Furthermore, the aetiology of hypertension involves the complex interplay of environmental and pathophysiological factors that affect multiple systems, as well as genetic predisposition. ${ }^{14} 15$ Thus, the impact of living environment and lifestyle changes on hypertension needs to be investigated.

The Ngawa Tibetan region is located in a transitional zone from the Qinghai-Tibetan plateau to the Sichuan basin. A significant proportion of the Tibetan population in Ngawa lives at a high altitude, low population density and economically less-developed areas. Also, the relative lack of medical resources contributes to a lack of health services provided in these area. However, with the medical reform plans ${ }^{16}$ and poverty alleviation ${ }^{17}$ of the government, the socioeconomic and primary healthcare in Ngawa has developed $^{18}$ (online supplemental figure S1). Consequently, the environment and lifestyle 
might alter the health disorders among the population, ${ }^{19}$ which cannot be captured by the existing data. Currently, there is a lack of epidemiological data regarding the change in hypertension among this population. Thus, the health status of people with income increases needs attention and management.

Therefore, the present study aimed to investigate the prevalence, awareness, treatment and control rates of hypertension and explored the putative factors associated with social environment and hypertension among Ngawa Tibetan whose income have been increased.

\section{METHODS}

\section{Design}

Cross-sectional observational study.

\section{Patient and public involvement}

The study protocol including the survey content was developed and designed with representatives from health management centre of Sichuan Provincial People's Hospital. Patients were not involved in the recruitment to and conduct of the study. The research results would be reported to study participants in future popular science lectures. This is not randomised controlled trials, and the burden of the investigation costs was assessed by the project funding. We are grateful to all study participants and advisers for their active cooperation in the acknowledgements.

\section{Participants}

Ngawa Tibetan Autonomous Prefecture is located in the northwest of Sichuan province of China and consists of 13 counties. In this study, the crosssectional investigation was based on a multistage stratified cluster sampling in the Ngawa area. The main settlements of Ngawa Tibetans across 13 counties were included randomly. According to the population proportion, the cluster sampling method was used to randomly select the counties and towns located in the east, west, north and south corners and the central part to carry out the population survey. All subjects were selected by random sampling method from one city (Maerkang) and six counties (Rangtang, Jinchuan, Aba, Hongyuan, Xiaojin and Maoxian) over the altitude range of 1500-3700 m. Pregnant or lactating women, patients with mental disorders and those unable to complete the survey due to physiological diseases were excluded from this study. The institutional review boards of the participating institutes approved the study protocol, and informed consent was obtained from the participants.

\section{Data collection procedure}

A standard structured questionnaire (online supplemental file 2) was prepared, which included demographical data such as age, gender, place of residence and education status. The history of hypertension and whether he received antihypertensive treatment was also recorded.

Five local Tibetan-speaking healthcare nurses were given adequate training in collecting physical measurements by a team of doctors. First, height and weight were measured in light indoor clothes without shoes. The body mass index (BMI) was calculated as weight in kilograms divided by height in metres squared $(\mathrm{kg} /$ $\mathrm{m}^{2}$ ). In addition, the blood pressure (BP) of each subject was measured twice on the right upper arm after at least 5 min of rest in a seated position using an automatic digital sphygmomanometer (Omron HBP9020, Kyoto, Japan), following the American National Management of Essential Hypertension and Chinese Hypertension guidelines. ${ }^{20}$

\section{Definitions}

Hypertension was judged as average systolic blood pressure $(\mathrm{SBP}) \geq 140 \mathrm{~mm} \mathrm{Hg}$ and/or average diastolic blood pressure (DBP) $\geq 90 \mathrm{~mm} \mathrm{Hg}$ and/or who had been previously diagnosed with hypertension or were currently taking antihypertensive medicines. According to the Chinese guidelines for Prevention and Control of Adult Overweight and Obesity, ${ }^{21}$ overweight was defined as BMI between 24 and $28 \mathrm{~kg} / \mathrm{m}^{2}$, and obesity was defined as BMI $\geq 28 \mathrm{~kg} /$ $\mathrm{m}^{2}$. The regular medical check-up was defined as a physical examination at least once every 2 years in public hospitals or clinics. Participants were asked to choose the diagnostic criteria for hypertension. If $\mathrm{SBP} \geq 140 \mathrm{~mm} \mathrm{Hg}$ or $\mathrm{DBP} \geq 90 \mathrm{~mm} \mathrm{Hg}$ could be correctly selected from the four alternative answers, the participant would be deemed to have a correct understanding of the diagnostic criteria for hypertension. Individuals who reported that a doctor or a health worker ever told them they had hypertension or those who were already on antihypertensive medications were recorded as 'known hypertensive'. Subjects were recorded on antihypertensive treatment if they confirmed that they were taking antihypertensive drugs. The control of hypertension was defined as patients with hypertension with SBP and DBP less than 140 and $90 \mathrm{~mm} \mathrm{Hg}$, respectively. The definitions of hypertension awareness, treatment and control rates are reported previously. ${ }^{22}$

\section{Data analysis}

Quantitative data were expressed as mean \pm SD and qualitative data as percentages. T-test and $\chi^{2}$ test were used to examine the differences in continuous and categorical variables, respectively. Multivariate logistic regression models were used to explore the correlation between baseline features and prevalence, awareness and control rate of hypertension. The data were entered (double entry) using EpiData V.3.0, and statistical analyses were performed using IBM SPSS Statistics V.19.0. The reported probabilities were two-sided, and $p$ value $<0.05$ indicated statistical significance. 


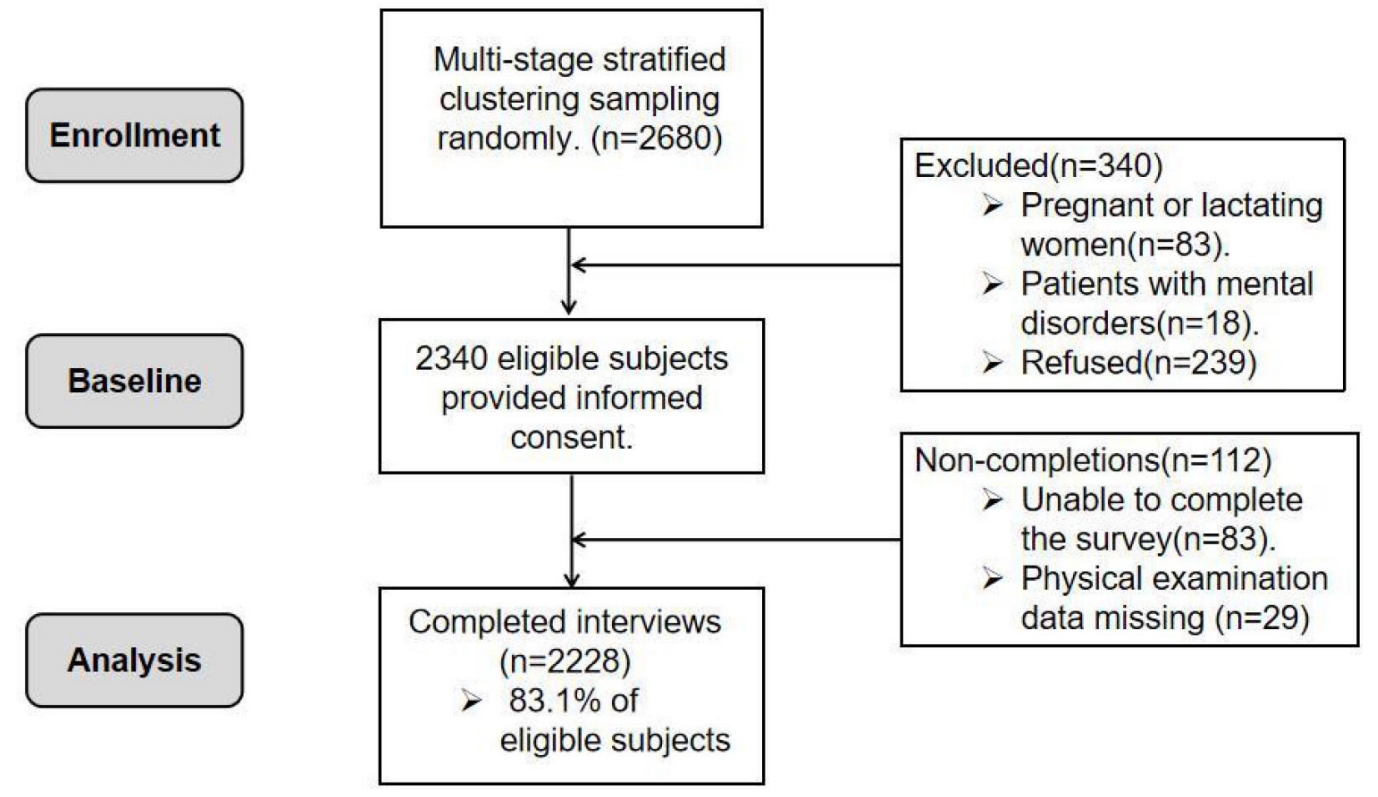

Figure 1 Participant flow chart.

\section{RESULTS}

\section{Participant characteristics}

A total of 2680 participants were invited to the survey. However, 239 subjects refused to participate. Finally, 2228 participants, aged $45.00 \pm 14.01$ years, completed the investigation. The response rate was $83.1 \%$. The participant flowchart is shown in figure 1 . The education level was low (about $40 \%$ of subjects had elementary school or lower education), and $63 \%$ of subjects reported being able to undergo regular physical examinations. Table 1 shows the demographical characteristics across gender.

Prevalence, awareness, treatment and control of hypertension and demographical characteristics

Based on the measurement values obtained at the interview, the mean SBP and DBP were $128.23 \pm 14.06$ and $79.08 \pm 10.89 \mathrm{~mm} \mathrm{Hg}$. Among all the subjects, 548 subjects were diagnosed to be hypertensive; $177 / 548$ were patients with hypertension who have been

Table 1 Characteristics of the sample

\begin{tabular}{|c|c|c|c|}
\hline Variable & Man $(n=1310), n(\%)$ & Woman (n=918), n (\%) & Total $(n=2228), n(\%)$ \\
\hline Age(years) & $47.15 \pm 14.29$ & $41.93 \pm 13.02$ & $45.00 \pm 14.01$ \\
\hline BMI $\left(\mathrm{kg} / \mathrm{m}^{2}\right)$ & $24.45 \pm 2.53$ & $22.25 \pm 2.81$ & $23.55 \pm 2.86$ \\
\hline Elementary school or lower & $506(42.6)$ & $325(36.5)$ & $831(40.0)$ \\
\hline Middle school & $214(18.0)$ & $141(15.8)$ & $355(17.1)$ \\
\hline \multicolumn{4}{|l|}{ Altitude $(\mathrm{m})$} \\
\hline $1500-2500$ & $346(26.4)$ & $142(15.5)$ & $488(21.9)$ \\
\hline 2500-3500 & $772(58.9)$ & $596(64.9)$ & $1368(61.4)$ \\
\hline$\geq 3500$ & $192(14.7)$ & $192(14.7)$ & $372(16.7)$ \\
\hline \multicolumn{4}{|l|}{ Region } \\
\hline \multicolumn{4}{|l|}{ Medical check-up regularly } \\
\hline Yes & $802(61.2)$ & $602(65.6)$ & $1404(63.0)$ \\
\hline No & $508(38.8)$ & $316(34.4)$ & 824 (37.0) \\
\hline
\end{tabular}

BMI, body mass index. 
diagnosed or had taken medication, and 371/548 were newly diagnosed with high blood pressure (HBP), that is, $16.7 \%$ of the population. The prevalence rate was $24.6 \%$, which was significantly higher in men $(30.0 \%)$ than in women $(p<0.0001)$. With the increasing age, the prevalence rate also showed a significant increase $(5.9 \%$ vs $29.6 \%$ vs $52.9 \%, \mathrm{p}<0.0001)$. The awareness rate was $32.3 \%$. Both the awareness and treatment rates in the 40-59 age group were highest among the three age groups. However, the treatment and control rates in our study were low $(21.7 \%$ and $6.2 \%$, respectively). Among the 177 participants who were aware of their hypertension, $56(31.64 \%)$ did not receive medical treatment, while five had blood pressure under control in this measurement. The analysis of the questionnaire information revealed that only $304(16.0 \%)$ subjects understood hypertension diagnosis standards correctly. While discussing the detrimental effects of hypertension on health, 1188 $(53.3 \%)$ subjects filled in 'not clear'. The prevalence, awareness, treatment and control of hypertension are shown in table 2 and figure 2.

\section{Multivariate analyses about prevalence, awareness and treatment of hypertension}

The prevalence, awareness and treatment rate of hypertension were correlated with gender, age, place of residence, altitude, family history of hypertension, weight, education level and regular medical check-up. The control rate of hypertension in this population was low $(6.2 \%)$, which was insufficient for further analysis. As a result, multivariate attributive analysis was performed on the prevalence, awareness and treatment rate of hypertension, which showed statistically significant differences (table 2). Figure 3 shows the results of the risk factors of prevalence, awareness, and treatment related to demographical characteristics.

\section{DISCUSSION}

The prevalence of hypertension in many studies among the Tibetan population in the highland areas is different $(23.4 \%-51.2 \%))^{9-13}$ Ngawa is located in the northwest of Sichuan province, a plateau area adjacent to Ganzi, where $>536000$ Tibetans resided. ${ }^{18}$ Ngawa Tibetan had the oldest altitude ancestry and living environment as other Tibetans: thin air, low oxygen partial pressure, salty meat and lesser intakes of fruits and vegetables. ${ }^{23}$ With the implementation of the government's poverty alleviation plan, the change in the socioeconomic and medical resources affected their lifestyle and the incidence of hypertension. To the best of our knowledge, this is the first study of hypertension in Ngawa, which provides the baseline survey data for future research and fills in the gap in this field.

The prevalence rate of hypertension among Ngawa Tibetan was $24.6 \%$, which was lower than that in Ganzi
Tibetan, but consistent with the result among the Chinese population $(23.2 \%) .^{7}$ About $33 \%$ of the Ngawa Tibetan $(32.2 \%)$ were aware of their hypertension. Although the awareness rate is still lower than the average level of other regions in China (40.7\%), ${ }^{7}$ compared with the previous surveys from Ganzi Tibetans $(7.5 \%)$, it had increased significantly in recent years, while the treatment and the control rates were still low ( $21.7 \%$ and $6.2 \%$, respectively). Moreover, the awareness, treatment and control rates of hypertension varied greatly even for the same race from different areas as China is a vast country. Also, hypertension was newly detected during the survey in about $16.7 \%$ of the population studied, which has major implications for public health measures towards diagnosis and treatment of hypertension. Although epidemiological studies relying on single-session measurements overdiagnose hypertension by $20 \%-25 \%,{ }^{22}$ it is becoming one of the primary public health problems in Sichuan Tibet areas. The government should undertake measurements for the prevention and control of hypertension in these regions.

The survey found greater awareness and treatment rates of hypertension compared with the data from rural areas in Sichuan in 2015 (24.7\% and $14.7 \%$, respectively). ${ }^{24}$ The prevalence of hypertension in the county was higher than that in the city, while the awareness and treatment rates in the county were significantly lower. After adjusting the multivariate regression model, no significant independent influence was noted on the prevalence (figure 3A). However, the urban-rural difference was the independent risk factor of awareness and the treatment of hypertension (figure 3B and C). Although this study did not find any significant difference in the prevalence and treatment of hypertension among people with or without regular physical examinations, the awareness rate was significantly higher among people undergoing regular physical examinations. Also, the higher the education of Tibetan residents, the lower the prevalence rate and the higher the awareness rate (figure $3 \mathrm{~A}$ and $\mathrm{B}$ ). Thus, we speculated that improving basic medical security and enhancing universal health education are effective in preventing and controlling hypertension.

Furthermore, an age-related increase was detected in the prevalence irrespective of gender; this finding was consistent with previous studies. ${ }^{11} 1322$ The decreased vascular patency and the deterioration of vascular elasticity in the aged might be one of the reasons for prevalence. ${ }^{7}$ In addition, the high prevalence of hypertension in young Tibetans should be noted, especially in men aged 18-30 years old. Based on their income increases, the lifestyle and living standards of the Ngawa Tibetan had changed. Fast food with high calories becomes readily available as the number of income-wealthy consumers grows, which is an increasing source of food. Reduced physical activity and high-calorie foods are the major contributing factors to the rise in body overweight and obesity. Some Ngawa Tibetans have abandoned husbandry and are pursuing a living in the urban environment, while some have retained pastoral lives, either by owning livestock under 
Table 2 Relationship between hypertension status and demographical characteristics

\begin{tabular}{|c|c|c|c|c|c|}
\hline Characteristics & $\mathbf{N}$ & Prevalence, N1 $(\%)^{*}$ & Awareness, N2 (\%)† & Treatment, N3 (\%)‡ & Control, N4 (\%)§ \\
\hline Subjects & 2228 & $548(24.6)$ & $177(32.3)$ & $119(21.7)$ & $34(6.2)$ \\
\hline \multicolumn{6}{|l|}{ Gender } \\
\hline Female & 918 & $155(16.9)$ & $35(22.6)$ & $24(15.5)$ & $8(5.2)$ \\
\hline$P$ value & & $<0.00019$ & $0.002 ף$ & 0.0269 & 0.525 \\
\hline \multicolumn{6}{|l|}{ Age (years) } \\
\hline $40-59$ & 942 & $279(29.6)$ & $116(41.6)$ & $78(28.0)$ & $22(7.9)$ \\
\hline $60-80$ & 410 & $217(52.9)$ & $56(25.8)$ & $39(18.0)$ & $11(5.1)$ \\
\hline$P$ value & & $<0.00019$ & $<0.00019$ & $<0.00019$ & 0.18 \\
\hline \multicolumn{6}{|l|}{ Education level } \\
\hline Elementary school or lower & 831 & $325(39.1)$ & $79(24.3)$ & $57(17.5)$ & $12(3.7)$ \\
\hline \multicolumn{6}{|l|}{ Family history } \\
\hline Yes & 182 & $98(53.8)$ & $62(63.5)$ & $55(43.9)$ & $9(9.2)$ \\
\hline No & 2046 & $450(22.0)$ & $115(25.6)$ & $76(16.9)$ & $25(5.6)$ \\
\hline$P$ value & & $<0.00019$ & $<0.00019$ & $<0.00019$ & 0.18 \\
\hline \multicolumn{6}{|l|}{ Altitude (m) } \\
\hline $1500-2500$ & 488 & $168(34.4)$ & $72(42.9)$ & $40(23.8)$ & $16(9.5)$ \\
\hline $2500-3500$ & 1368 & $252(18.4)$ & $82(32.5)$ & $58(23.0)$ & $15(6.0)$ \\
\hline$\geq 3500$ & 372 & $128(34.4)$ & $23(18.0)$ & $21(16.4)$ & $3(2.3)$ \\
\hline$P$ value & & $<0.00019$ & $<0.00019$ & 0.25 & 0.039 ๆ \\
\hline$\geq 28$ (obesity) & 136 & $71(52.2)$ & $42(59.2)$ & $14(19.7)$ & $2(2.8)$ \\
\hline$P$ value & & $<0.00019$ & $<0.00019$ & 0.029 & 0.22 \\
\hline \multicolumn{6}{|l|}{ Medical check-up regularly } \\
\hline Yes & 1404 & $268(19.9)$ & $99(38.7)$ & $73(28.5)$ & $17(6.6)$ \\
\hline No & 824 & $280(34.0)$ & $78(26.7)$ & $46(15.8)$ & $17(5.8)$ \\
\hline$P$ value & & $<0.0001 \rrbracket$ & $0.003 \rrbracket$ & $<0.00019$ & 0.69 \\
\hline $\begin{array}{l}{ }^{*} \mathrm{~N} 1 / \mathrm{N}^{*} 100 \% . \\
+\mathrm{N} 2 / \mathrm{N} 1^{*} 100 \% \\
\text { fN3 } 3 / \mathrm{N1}^{1} 100 \% \\
\S \mathrm{N} 4 / \mathrm{N} 1^{1} 100 \%\end{array}$ & & & & & \\
\hline
\end{tabular}

the care of others or by moving intermittently between urban and pastoral settings. Thus, the current urban food environment and lifestyle could effectuate changes in health among the population, especially young people. ${ }^{25}$ Thus, the health-related behaviours in young people, such as smoking, alcoholism and eating habits, should be under intensive focus.

Some investigators have assessed the impact of altitude on blood pressure. ${ }^{26}$ The studies suggested that chronic exposure to a hypoxic environment at high altitudes $(\geq 3500 \mathrm{~m})$ caused increased sympathetic and parasympathetic activities, which in turn raised the blood pressure. ${ }^{26}$ Research across the Tibetan regions indicated a significant correlation between altitudes (3000-4300 m) and the prevalence of hypertension among Tibetans. ${ }^{10}$ However, another survey in Ladakh and Northern India reported that the prevalence of hypertension in Tibetan nomads living at higher altitudes (4000-4900 m) was 

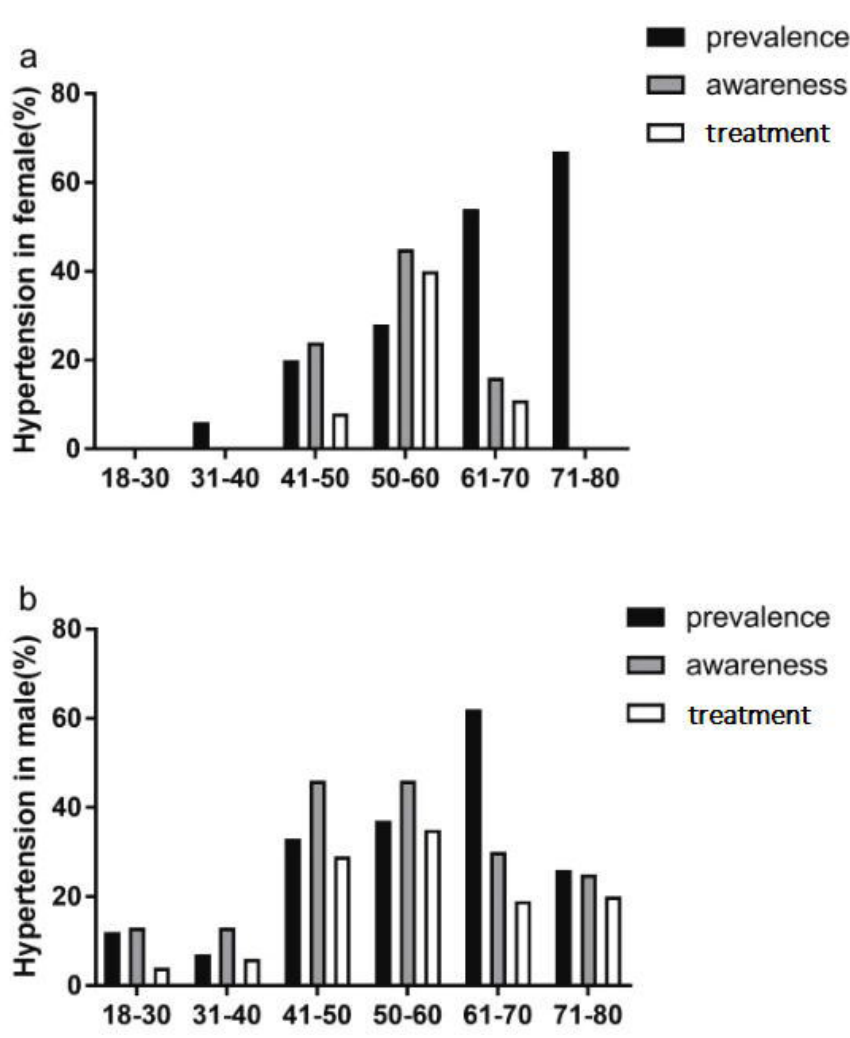

Figure 2 The prevalence, awareness and treatment rate of hypertension. (A) Hypertension in woman. (B) Hypertension in man. *Prevalence was defined as subjects had an average $\mathrm{SBP} \geq 140 \mathrm{mmHg}$, and/or average $\mathrm{DBP} \geq .90 \mathrm{mmHg}$, and/ or were diagnosed as being hypertensive in the past, and/or reported current treatment with anti-hypertensive medications among the population. Awareness was defined as self-reporting any prior diagnosis of hypertension by health care professionals among the population who were defined as being hypertensive. Treatment was defined as the use of an anti-hypertensive medication at the time of the interview or during the previous year for hypertension among the population who were defined as being hypertensive.

relatively low (19.7\%). ${ }^{27}$ Some studies contributed to the socioeconomic and cultural factors underlying hypertension. The genetic adaptation among Tibetan people found that three inducible nitric oxide synthase (NOS3) and alpha-adducin-1 $(A D D)$ genes were related to a high incidence of hypertension. ${ }^{10}$ The NOS3 gene variation is associated with a low-oxygen environment, and the altered $A D D$ gene is consistent with the high-salt diet of Tibetans. In the current study, the prevalence of hypertension decreased, followed by an increase as the altitude rises from $1500 \mathrm{~m}$ to $\geq 3500 \mathrm{~m}$ ( $34.4 \%$ vs $18.4 \%$ vs $34.4 \%$, $\mathrm{p}<0.0001$; table 2 and figure 3A). The reasons for this trend are unclear. Future investigations could study the synergy of genetic adaptation, changes in socioeconomic or cultural factors and the prevalence of hypertension.

The awareness and treatment rates among women in Ngawa were lower than those mentioned studies. ${ }^{28}$ This might be because of Tibetan women were mostly housewives and not paying attention to their health. Therefore, strengthening their health education could increase the awareness and treatment rates of the women in Ngawa.

Moreover, the control rate of hypertension in the city and county was low $(7.7 \%$ and $5.4 \%$, respectively). No significant difference was observed in the gender, age and weight groups (table 2 and figure 3C). The higher the altitude and/or the lower the education level, the lower the control rate. This might prompt the government to improve primary care in high-altitude and low-education level areas in the control rate of hypertension.

Other risk factors correlated with the prevalence of hypertension collected in this survey mainly include the family history of hypertension, overweight and obesity (figure 3A). Obese and overweight patients have a higher prevalence and awareness of hypertension but a lower control rate. This phenomenon was consistent with that described previously. ${ }^{21}{ }^{28}$ Hypertension is hereditary and related to family genes, living habits, eating habits and other factors. Subjects with a family history of hypertension had a 3.86-fold higher risk of hypertension. However, their awareness and treatment rate were also higher. Thus, the high risk of the disease might gain their attention and prompt them to be proactive in the treatment. Limited by funding and other objective conditions, the sample size collected in this survey was small, and we had not obtained blood glucose, blood lipids, diet and physical activity levels. Therefore, in the future, large-scale epidemiological investigations are required among the population in the specific region.

Among the 177 participants who are aware of their HBP, 56 subjects did not receive medical treatment (31.64\%), while five subjects had normal blood pressure in this measurement. This might be because they changed their lifestyles after the diagnosis, ${ }^{15}$ or it may be that these individuals have reported that they had hypertension without clearly understanding the disease being referred to. The existing data cannot further analyse the reasons. In future surveys, for self-reported patients with hypertension, if participants could provide any documented evidence to prove the diagnosis of hypertension or inspection of the actual medications being taken, the analysis data would be more accurate. In the questionnaire, we can add 'whether lifestyle intervention has been done' to assist in the analysis.

Nevertheless, the present study has several limitations that should be considered while interpreting the findings. First, it was a cross-sectional study and, hence, limited in determining the direction of the association, as the exposure and the outcomes are simultaneously assessed. Thus, prospective studies are required for further investigation of these findings. However, this is the first survey on the hypertension of Ngawa Tibetan after the government's poverty alleviation, which could provide evidence-based data for future research. Second, it was difficult to exclude the possibility of bias in self-reporting because some participants could not tell whether they had HBP or what medicine they were taking. Although investigators had tried their best to assist in the diagnosis by asking for details of 
a. prevalence

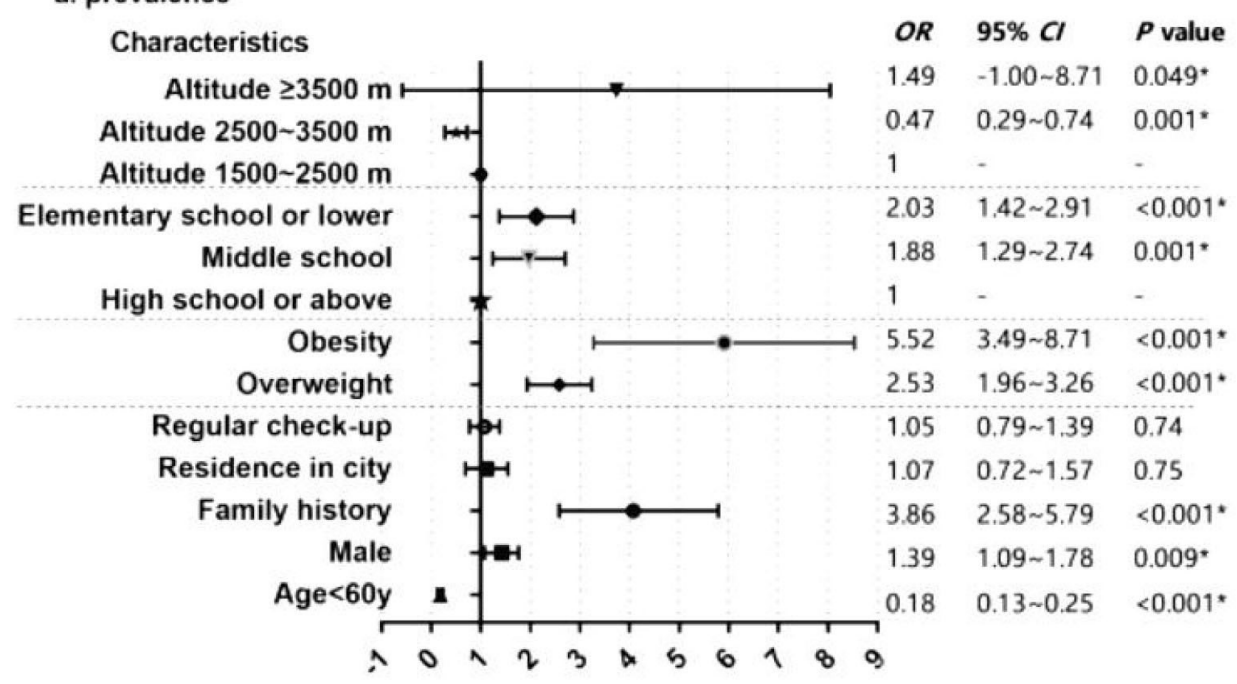

b. Awareness

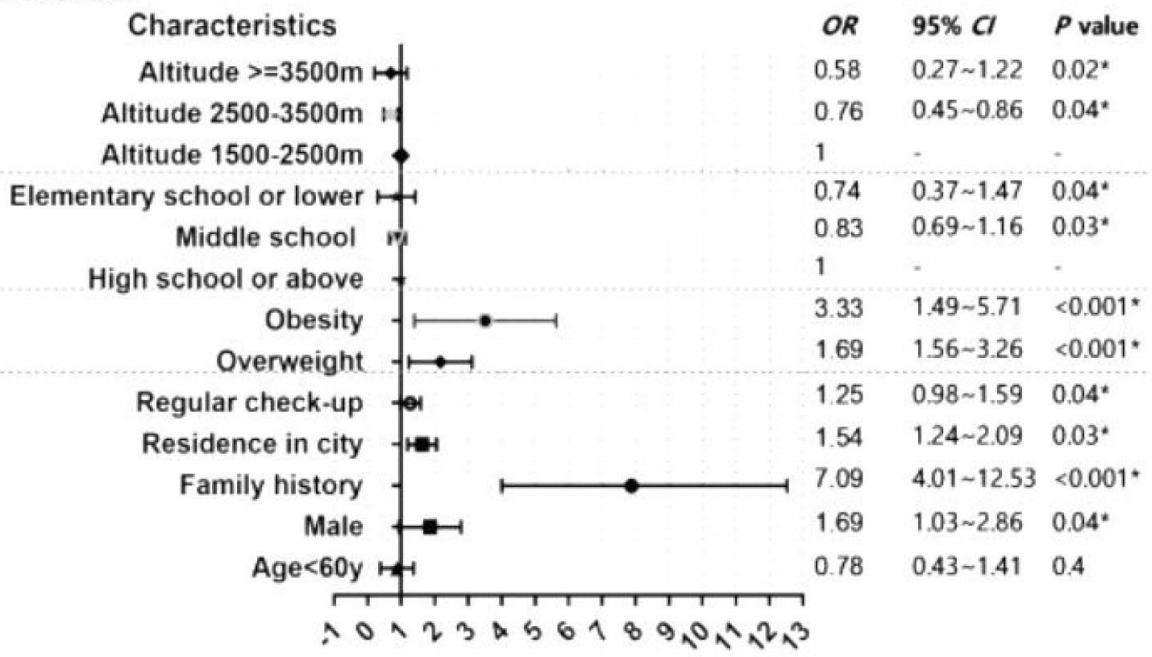

\section{Treatment}

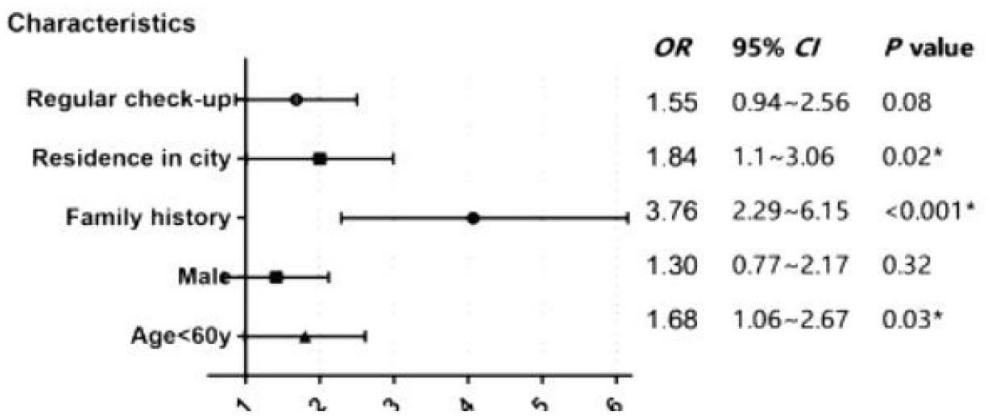

Figure 3 The $\mathrm{OR}$ and $95 \% \mathrm{Cl}$ from multiple logistic regression. (A) The prevalence rate of hypertension. (B) The awareness rate of hypertension. (C) The treatment rate of hypertension. ${ }^{*} \mathrm{P}<0.05$ was considered statistically significant.

the disease and promoting the name of the drug that may be taken, the error in the hypertension figures may be due to inaccuracy or omission. Third, limited by objective conditions, such as funding, the sample size of this survey was small; no random sampling of the population was stratified by age; and no blood index, diet, exercise and other data were collected. Some of the selected residents, especially those aged $>70$ years old, were reluctant for a check-up and to fill out the questionnaire, which might lead to missing data for older people and bias the results. Fourth, the prevalence of hypertension was based on the measurements of BP on a single day. The possibility of white-coat hypertension in some of these subjects (especially newly diagnosed) could not be excluded. Finally, a lack of information on comorbidities, such as diabetes, hyperlipidaemia, renal disease and lifestyle factors, such 
as diet and physical activities, limited further interpretation of the data. Therefore, additional epidemiological studies are needed to obtain comprehensive information and data to develop appropriate prevention strategies and controls.

\section{CONCLUSIONS}

The prevalence of hypertension among Ngawa Tibetan was high. The awareness and treatment rates were improved in recent years, while the control rate needed to be improved. This study, for the first time, analysed the hypertension data and potential social environment factors among Ngawa Tibetans, which provided evidencebased data on hypertension for future research. The government needs to strengthen the construction of basic medical care and health education for residents in Ngawa to develop population-based hypertension detection and control strategies. These could include increasing clinics, providing local medical staff with the diagnosis and treatment capabilities, enhancing education on the adverse outcomes of hypertension and encouraging medical follow-up for monitoring the BP in those already diagnosed with hypertension.

Acknowledgements We are grateful to all study participants and advisers for their active cooperation. We acknowledge contribution of our survey team members, interviewers, leaders and volunteers for their continuous efforts in the field survey.

Contributors Conceptualisation, TL and SP; methodology and writing—original draft preparation, TL; validation, WL; investigation, WJ; writing — review and editing, WJ and WL.

Funding This study was supported by Health Department of Sichuan Province (No. 2018-228 and No.20PJ107) and the National Key R\&D Program of China (No. 2017YFC0113901).

Competing interests None declared.

Patient consent for publication Not required.

Ethics approval The study was approved by the ethics committee of Sichuan Provincial People's Hospital (approval number: 2018-237), China.

Provenance and peer review Not commissioned; externally peer reviewed.

Data availability statement № data are available. No data are available. Researchers interested in collaboration should contact the corresponding author with their expression of interest.

Supplemental material This content has been supplied by the author(s). It has not been vetted by BMJ Publishing Group Limited (BMJ) and may not have been peer-reviewed. Any opinions or recommendations discussed are solely those of the author(s) and are not endorsed by BMJ. BMJ disclaims all liability and responsibility arising from any reliance placed on the content. Where the content includes any translated material, BMJ does not warrant the accuracy and reliability of the translations (including but not limited to local regulations, clinical guidelines, terminology, drug names and drug dosages), and is not responsible for any error and/or omissions arising from translation and adaptation or otherwise.

Open access This is an open access article distributed in accordance with the Creative Commons Attribution Non Commercial (CC BY-NC 4.0) license, which permits others to distribute, remix, adapt, build upon this work non-commercially, and license their derivative works on different terms, provided the original work is properly cited, appropriate credit is given, any changes made indicated, and the use is non-commercial. See: http://creativecommons.org/licenses/by-nc/4.0/.

ORCID iD

Lin Wang http://orcid.org/0000-0001-8114-1363
REFERENCES

1 GBD 2013 Mortality and Causes of Death Collaborators. Global, regional, and national age-sex specific all-cause and causespecific mortality for 240 causes of death, 1990-2013: a systematic analysis for the global burden of disease study 2013. Lancet 2015;385:117-71.

2 GBD 2016 Mortality Collaborators. Global, regional, and national under-5 mortality, adult mortality, age-specific mortality, and life expectancy, 1970-2016: a systematic analysis for the global burden of disease study 2016. Lancet 2017;390:1084-150.

3 DeGuire J, Clarke J, Rouleau K, et al. Blood pressure and hypertension. Health Rep 2019;30:14-21.

4 Mills KT, Stefanescu A, He J. The global epidemiology of hypertension. Nat Rev Nephrol 2020;16:223-37.

5 Kearney PM, Whelton M, Reynolds K, et al. Global burden of hypertension: analysis of worldwide data. Lancet 2005;365:217-23.

6 Bao C, Mayila M, Ye Z, et al. Forecasting and analyzing the disease burden of aged population in China, based on the 2010 global burden of disease study. Int J Environ Res Public Health 2015;12:7172-84.

7 Wang Z, Chen Z, Zhang L, et al. Status of hypertension in China: results from the China hypertension survey, 2012-2015. Circulation 2018;137:2344-56.

8 Bhatnagar A. Environmental determinants of cardiovascular disease. Circ Res 2017;121:162-80.

9 Huang X, Zhou Z, Liu J, et al. Prevalence, awareness, treatment, and control of hypertension among China's Sichuan Tibetan population: a cross-sectional study. Clin Exp Hypertens 2016;38:457-63.

10 Mingji C, Onakpoya IJ, Perera R, et al. Relationship between altitude and the prevalence of hypertension in Tibet: a systematic review. Heart 2015;101:1054-60.

11 Zhao X, Li S, Ba S, et al. Prevalence, awareness, treatment, and control of hypertension among herdsmen living at $4,300 \mathrm{M}$ in Tibet. Am J Hypertens 2012;25:583-9.

12 Zheng X, Yao D-K, Zhuo-Ma C-R, et al. Prevalence, self-awareness, treatment, and control of hypertension in Lhasa, Tibet. Clin Exp Hypertens 2012;34:328-33.

13 Zhang HT, Gao L, Long G. A survey of the prevalence and classification of cerebrovascular diseases in Ganzi Tibetan autonomous Prefecture, Sichuan Province. Chin J Cerebrovasc Dis 2018;15:35-9.

14 Waken RJ, de Las Fuentes L, Rao DC. A review of the genetics of hypertension with a focus on gene-environment interactions. Curr Hypertens Rep 2017;19:23.

15 Oparil S, Acelajado MC, Bakris GL, et al. Hypertension. Nat Rev Dis Primers 2018;4:18014.

16 Yip WC-M, Hsiao WC, Chen W, et al. Early appraisal of China's huge and complex health-care reforms. Lancet 2012;379:833-42.

17 CGTN. Zero poverty: China eliminates absolute poverty one month before self-imposed deadline, 2020. Available: https://news.cgtn. com/news/2020-11-23/China-eliminates-absolute-poverty-onemonth-before-schedule-VEp8VAJJS0/index.html

18 Statistics Bureau of Sichuan Provincial. Sichuan statistics year book (2014-2019). Available: http://tjj.sc.gov.cn/scstjj/c105855/nj.shtml

19 Craig PS, Giraudoux P, Wang ZH, et al. Echinococcosis transmission on the Tibetan Plateau. Adv Parasitol 2019;104:165-246.

20 Ferdinand KC, Nasser SA. Management of essential hypertension. Cardiol Clin 2017;35:231-46.

21 Tang D, Bu T, Feng Q, et al. Differences in overweight and obesity between the North and South of China. Am J Health Behav 2020;44:780-93.

22 Banerjee S, Mukherjee TK, Basu S. Prevalence, awareness, and control of hypertension in the slums of Kolkata. Indian Heart $J$ 2016;68:286-94.

23 Huang X, Zhou Z, Liu J, et al. Prevalence, awareness, treatment, and control of hypertension among China's Sichuan Tibetan population: a cross-sectional study. Clin Exp Hypertens 2016;38:457-63.

24 Wu X, Li L, Chen X, et al. [Characteristics of hypertension prevalence and related factors in rural area in Sichuan]. Zhonghua Liu Xing Bing Xue Za Zhi 2015;36:1216-9.

25 Li Y, Guo L-X, Zhou Q-Z, et al. Characterization of humic substances in the soils of ophiocordyceps sinensis habitats in the Sejila Mountain, Tibet: implication for the food source of Thitarodes larvae. Molecules 2019;24:246.

26 Bilo G, Caravita S, Torlasco C, et al. Blood pressure at high altitude: physiology and clinical implications. Kardiol Pol 2019;77:596-603.

27 Norboo T, Stobdan T, Tsering N, et al. Prevalence of hypertension at high altitude: cross-sectional survey in Ladakh, Northern India 2007 2011. BMJ Open 2015;5:e007026. 
28 Noubani A, Nasreddine L, Sibai AM, et al. Prevalence, awareness, and control of hypertension in greater Beirut area, Lebanon. Int $J$ 